\title{
Online Occupational Stress Intervention System for Academics
}

\author{
Mare Teichmann, Jüri Ilvest Jr., Ivar Soone \\ Department of Industrial Psychology \\ Tallinn University of Technology \\ Tallinn, Estonia
}

\begin{abstract}
This paper has outlined a new web-based intervention system for university academics. In particular, the paper addresses the evidence-based aspects of occupational stress in technical university academics. The novelty of the online system is in multiple-choice approach considering both primary and secondary level stress interventions. The users have a possibility to get information about their own stress level and about the specific occupational stressors by using stress test (AcadOSI), to learn coping with stress by using digital teaching tools and sources of relevant information, and finally the users receive video-based instructions for better coping with most intensive sources of stress. In academic life it means the occupational stress management trough better workflow planning, personal work-life balance activities, evaluating the necessity of bureaucracy in university, enhancing relationships with students, peers and management, and working on constant professional development.
\end{abstract}

Keywords-occupational stress; technical university academics; coping with stress; occupational stress intervention

\section{OCCUPATIONAL STRESS IN UNIVERSITY ACADEMICS}

Work-related stress is a growing problem that results in substantial cost to employees and work organizations all over Europe. Work-related stress is caused by and contributes to major environmental, economic, and health problems [1, 2]. Moreover, the situation has not significantly improved over the past decade.

University teaching has traditionally been regarded as a low-stress occupation. Growing empirical evidence proves that this may be true from a historical point of view, but not so at modern universities where occupational stress is a growing problem $[3,4,5]$. The changing nature of the work presents academics and their work organization today with higher demands than ever before. In most European universities, for example, the 2010s were a period of dramatic downsizing, funding cuts, and globalization. This has lead to greater academic mobility, increased global competition, and dramatic changes in academic culture in general. All these transformations have been coupled with rapid technological change and a strong push for greater efficiency, increased competitiveness, and stricter expectations for students in academic life $[6,7,8]$. Conventional wisdom suggests that it is this climate of continual change that is placing many academics under pressure and creating changes in the academic culture of universities. Furthermore, the empirical findings suggest that the main sources of stress in university are heavy teaching loads or teaching work overload; funding cuts and declining resources; organizational changes; poor management practices; and job insecurity $[9,10,11]$. None of the premillennium literature sources mentioned, for example, organizational change as a source of stress in university.

With some notable exceptions occupational stress in technical university academics has received little empirical attention in literature. Niven and Cutler [12] found that job satisfaction and stress-related measures of mental health and physical health of the full-time teaching staff from a former polytechnic did not differ significantly from other university academic personnel. Brewer and McMahan-Landers [13] report industrial and technical teacher educators perceived stressors related to lack of organizational support as more severe than stressors related to the job itself. Also, participants reported an average degree of occupational stress. Ramage [14] surveyed teaching staff at a polytechnic and identified organizational structure and climate, role conflict and relationships at work as influential stress sources, and HardieBoys [15] concluded similarly that institutional climate and morale, workload, interruptions to work, and management were among the major stressors for polytechnics' teachers. Interestingly, the lack of relief staffing was the most frequently mentioned stressor; funding and resourcing were also stressors mentioned in this survey, and a common factor, as elsewhere, was the impact of educational and organizational change.

\section{SOURCES OF OCCUPATIONAL STRESS IN TECHNICAL UNIVERSITY ACADEMICS}

Research carried out in Tallinn University of Technology (TUT) and University of Bordeaux, ENSEIRB-MATMECA showed a framework of sources of pressure that consisted of 90 separable stressors. Statistical treatment of the research results in eight factors with interfactor correlations ranging from 0.33 to 0.67 (the rotation converged in eight iterations $\mathrm{R}^{2}=0.53 ; \mathrm{p}<$ $0.0001)$. The factor structure comprises of one factor on the individual level (i.e. Personal life and professional identity), one on the academic community level (i.e. Evaluation of Knowledge in Society), and six factors on the work and organizational level (i.e. Workload; Students and Teaching; Professional Development, University Life and Social Relationships; Infrastructure at University, and Bureaucracy) [16]. Compared to the previous empirical findings described in literature, this study uncovered a remarkably wider range of 
different sources of stress in technical university academics. It revealed that the sources of stress were neither universityspecific and nor culture-specific. The research shows that all 90 sources of stress were involved as stressors for academics at TUT as well at the University of Bordeaux' faculties of science and engineering [17].

In both academic groups the average occupational stress level was high - more than one third of academic staff members suffered from work stress; in TUT this indicator reached 38.93 percent and at the University of Bordeaux 38.98 percent.

When comparing the work stressors of the academic staff of different universities, differences were found in the intensity of sources of pressure. Comparing the work stressors of the TUT academic staff with the work stressors of the academic staff at the University of Bordeaux, statistically significant differences were found in the intensity of sources of pressure (Table 1).

TABLE I. DIFFERENCE OF INTENSITY OF STRESSORS

\begin{tabular}{|c|c|c|c|c|c|}
\hline \multirow{2}{*}{$\begin{array}{c}\text { Occupational stress } \\
\text { factors }\end{array}$} & \multicolumn{2}{|c|}{$\begin{array}{l}\boldsymbol{T U} \boldsymbol{T} \\
(N=458)\end{array}$} & \multicolumn{2}{|c|}{$\begin{array}{l}\text { University } \\
\text { of Bordeaux } \\
(N=44)\end{array}$} & Difference \\
\hline & Mean* & $S D$ & Mean* & $S D$ & $\begin{array}{l}\text { Student } \\
\text { t-test }\end{array}$ \\
\hline $\begin{array}{l}\text { 1. University Life and } \\
\text { Social Relationships } \\
\text { (24 items) }\end{array}$ & 3.02 & 1.05 & 3.29 & 0.93 & $\mathrm{p}=0.08$ \\
\hline $\begin{array}{l}\text { 2. Students and } \\
\text { Teaching ( } 20 \text { items) }\end{array}$ & 2.87 & 0.97 & 2.58 & 0.60 & $\mathrm{p}<0.01$ \\
\hline 3. Workload (9 items) & 3.45 & 1.09 & 3.87 & 0.83 & $\mathrm{p}<0.01$ \\
\hline $\begin{array}{l}\text { 4. Personal Life and } \\
\text { Professional Identity } \\
\text { (9 items) }\end{array}$ & 2.58 & 0.95 & 2.34 & 0.76 & $\mathrm{p}=0.06$ \\
\hline $\begin{array}{l}\text { 5. Evaluation of } \\
\text { Knowledge in Society } \\
\text { (9 items) }\end{array}$ & 3.72 & 1.08 & 3.21 & 0.96 & $\mathrm{p}<0.01$ \\
\hline $\begin{array}{l}\text { 6. Bureaucracy (10 } \\
\text { items) }\end{array}$ & 3.22 & 0.95 & 3.89 & 0.85 & $\mathrm{p}<0.01$ \\
\hline $\begin{array}{l}\text { 7. Personal } \\
\text { Development (4 items) }\end{array}$ & 2.70 & 0.97 & 3.43 & 0.71 & $\mathrm{p}<0.01$ \\
\hline $\begin{array}{l}\text { 8. Infrastructure at } \\
\text { University (5 items) }\end{array}$ & 2.85 & 1.08 & 2.47 & 0.86 & $\mathrm{p}<0.01$ \\
\hline
\end{tabular}

*Six-point response scale: "very definitely is not a source of pressure" (1 point) and "very definitely is a source of pressure" (6 points)

The intensity levels of two factors, namely University Life and Social Relationships, and Personal Life and Professional Identity were quite similar. However, the intensity levels of other six occupational stress factors were significantly different.

In order to identify the sources of pressure are for technical university academics, we calculated and summarized the following responses in the 6-point scale: (4) Generally is a source of pressure; (5) Definitely is a source of pressure; and (6) Very definitely is a source of pressure. On the basis of percentage of academics suffering from work-related stressors we draw out the occupational stress profile of university (Fig. $1)$.
In the occupational stress profile of Bordeaux University's faculties of science and engineering the major sources of stress were high workload ( $61.5 \%$ of academics respond that it is a source of pressure), personal development (48.5\% indicated it as a source of pressure), and bureaucracy $(60.7 \%$ of academics).

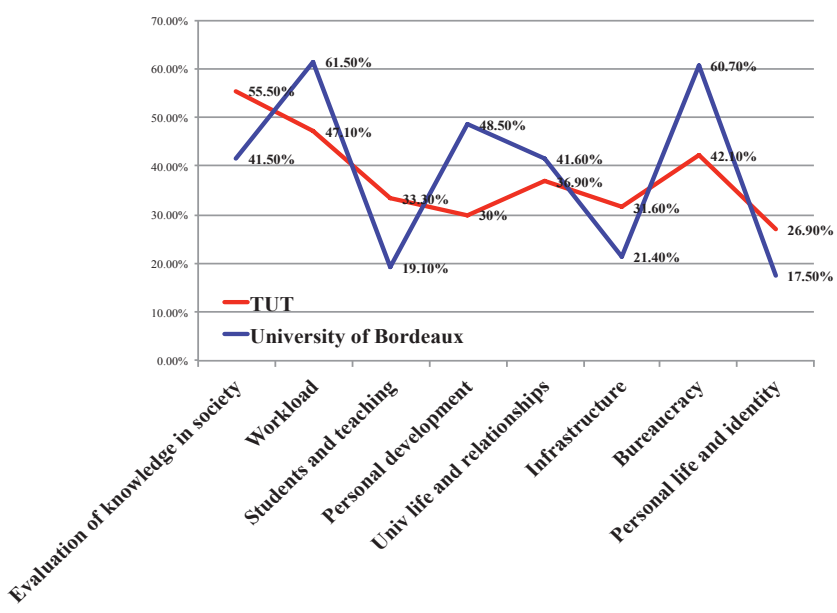

Fig. 1. The Sources of Pressure for Academic Staff

At TUT, on the other hand, the main occupational stressors were evaluation of knowledge in society $(55.5 \%$ academics respond that it is a source of pressure), high workload (47.1\% of academics indicated it as a source of pressure), and bureaucracy ( $42.1 \%$ respectively). This leads us to conclusion that sources of pressure were very similar in content but the intensity of different sources of pressure in academic life in Estonia and in France was in majority areas different.

However, the number of different sources of occupational stress in technical university could be eliminated or their stressful influence on academics minimized. Knowing the exact profile of sources of stress in technical university academics would make it possible to plan and evaluate occupational stress prevention and intervention methods in university. These new developments further highlight a focus on sources of stress in university, as it is one of the key issues for occupational stress intervention.

\section{OCCUPATIONAL STRESS INTERVENTION AND COPING WITH STRESS}

There are three levels suggested for occupational stress intervention [18, 19, 20,21]. Primary level occupational stress intervention focuses on dealing with stressors. According to our research results, dealing with stressors in university means better workflow planning, work-life balance initiatives, evaluating the necessity of bureaucracy in university, enhancing relationships with students, peers and management, renovating infrastructure in university, and working on constant professional development. 
Secondary level occupational stress intervention addresses helping people to cope with stress. This level includes resilience training, stress management courses, annual reviews and appraisals, and personal developments plans, and wellbeing programs in university. Our research results suggest that increasing coping knowledge among academics could help them to create more adaptive and effective coping styles.

Coping is expending conscious effort to solve personal and interpersonal problems, and seeking to master, minimize, influence or tolerate the occupational sources of stress. Coping responses are partly controlled by personal habitual traits, but also partly by the social context, particularly the nature of the stressful environment [22].

About 400 to 600 different coping strategies have been identified. Classification of these strategies into a broader architecture has not yet been agreed upon. There exists some agreement among researchers regarding three broad types of coping strategies: (a) appraisal-focused (adaptive cognitive), (b) problem-focused (adaptive behavioral), and (c) emotionfocused [23]. Appraisal-focused strategies occur when the persons modify the way they think, for example: employing denial or distancing oneself from the problem. People may alter the way they think about a problem by altering their goals and values, such as by seeing humor in a situation. People using problem-focused strategies try to deal with the cause of their problem. They do this by seeking information about the problem and learning new skills to manage it. Problemfocused coping is aimed at changing or eliminating the source of the stress. Emotion-focused strategies involve releasing pent-up emotions, distracting oneself, managing hostile feelings, meditating, or using systematic relaxation procedures. Emotion-focused coping is oriented toward managing the emotions that accompany the perception of stress [24].

The tertiary level of occupational stress intervention is the process utilized to pick people back up, e.g. employee assistance programs for rehabilitation. Employee assistance programs are intended to help employees to deal with personal problems that might adversely impact their work performance, stress, physical and mental health, and wellbeing. Employee assistance programs generally include short-term counseling and referral services for employees and members of their household.

Preventive measures and intervention for occupational stress in technical university academics can be addressed on three levels. On individual level, i.e. by learning to cope better with occupational stress specifically and with stress in general, the individual can prevent the negative psychological effects of occupational stressors. On university organizational level (i.e. by changing the work situation through organizationbased interventions), the source of the problems is tackled and the employee's negative reaction is reduced, and the employee's resistance to specific occupational stressors is increased. And finally, on societal level in Europe, Occupational Health and Safety Services (OHSS) have been facilitated by the introduction of new occupational health and safety legislation. The OHSS organizations play an indirect role in reducing occupational stress in at least three ways: (1) by regularly carrying out stress audits and personal screenings; (2) by offering specialized individual counseling and rehabilitation service for employees with work-related mental problems; (3) through expert consultations in occupational medicine, safety engineering, human factors, and occupational psychology.

Traditionally there are mainly two occupational stress interventions in use - dealing with the stressors and helping people cope with occupational stress [25].

\section{ONLINE INTERVENTION SYSTEM FOR ACADEMICS}

The online occupational intervention system was originally launched in the autumn 2006 for engineers [26]. In 2007, a new system for TUT academic staff was introduced [27], which is available in online (http://stress.enop.ee/) free of charge for all users. Depending on occupational stress survey results the system has been continuously improved.

The system was developed for decreasing occupational stress by offering psycho-diagnostics, knowledge, advice and guidance to enable coping. The system includes: (1) the Academic Occupational Stress Indicator (AcadOSI), (2) individual feedback for every user, and (3) two digital teaching tools on "Occupational Stress" and "Coping with Stress". Simultaneously with fresh empirical findings, the system was developed, and (4) the sources of relevant information (mainly papers regarding work-related stress and coping with occupational stress), and (5) video-based instructions for coping with occupational stress for technical university academic staff (i.e. evaluation of knowledge in society, workload, students and teaching, professional development, university life and relationships, infrastructure at university, bureaucracy, personal life (work-life balance) and professional identity) were added (Fig. 2).

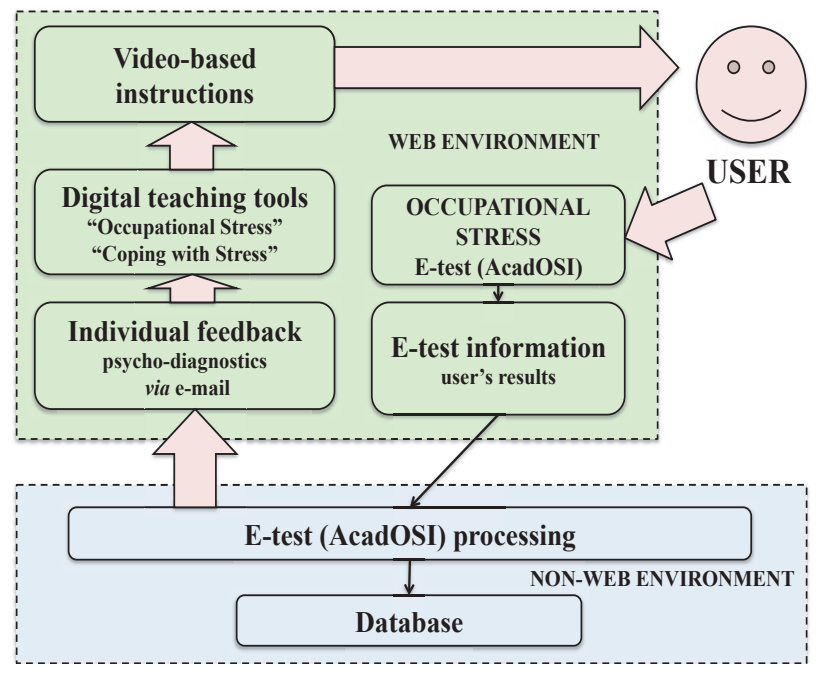

Fig. 2. Online Occupational Stress Intervention System for Technical University Academics 


\section{A. The Academic Occupational Stress Indicator (AcadOSI)}

The AcadOSI comprises of 156 items which contain the measures of job satisfaction (divided into two subscales: satisfaction with the job itself and satisfaction with the organization, 12 items); mental well-being (divided into three subscales: contentment, resilience, and peace of mind, 12 items); physical well-being (divided into two subscales calmness, and energy, 6 items); A-type behaviour (6 items); locus of control (4 items); sources of pressure in the job (divided into eight job stressors, i.e.: university life and social relationships, 24 items), students and teaching (20 items), workload ( 9 items), personal life and professional identity ( 9 items), evaluation of knowledge in society (9 items), bureaucracy (10 items), professional development (4 items), university infrastructure (5 items); coping with occupational stress (divided into two subscales: control over stress, 6 items, and social support, 4 items respectively), and the Work Locus of Control Scale (total of 16 items).

The Work Locus of Control Scale [28] assesses employee's beliefs about their control at work in general. Half of the items measure external locus of control, whereas the other half indicate internal locus of control. Work Locus of Control reflects the individual's tendency to believe that they control events in their working life (internality) or that such control resides elsewhere, e.g. with powerful others (externality).

Originally, OSI-2 test was designed as a measurement tool for managerial stress. In the present study, we replaced only one part of the OSI-2 test, namely sources of pressure at managers' job was replaced with another checklist comprising 90 separable sources of pressure at university academics jobs. The validity and reliability of OSI- 2 has been tested and reported about in various CISMS publications [29, 30].

\section{B. Individual Feedback for AcadOSI Test User}

The Academic Occupational Stress Indicator (AcadOSI) is available online. The user answers the AcadOSI test questions in Web environment and completed test is automatically sent to the recipient by e-mail once the user pushes the "send" button.

This user's answers are then removed from the Web environment since according to the test manual, processing of the AcadOSI test takes place offline. This ensures that test key's and authors' copyright are not violated and the confidentiality of the user's test results is guaranteed. The data of the final test results are copied into and kept in a database outside the Web environment. The processed results of the AcadOSI test are sent individually to each user to her/his email address within 2-3 minutes after completion of the test. The time delay occurs due to security reasons since the answers to the AcadOSI test have to be copied into offline database, processed and transferred to a suitable format for returning to the user. The length of the delay depends on the recipient's Internet connection and speed. The Internet links for access to e-learning facilities and the digital teaching tools "Occupational Stress" and "Coping with Stress" are attached to the test results returned to the user.

\section{Digital Teaching Tools}

The digital teaching tool is a special unit of a specific topic. Both digital teaching tools, "Occupational stress" and "Coping with stress" include a video-based lecture, slides presented at the lecture and written materials for reading. A MP3 audio version and DVD option of the lectures are available for users.

The digital teaching tools discuss stress at work addressing theoretical background of occupational stress, burnout, occupational stress risk, and stressors at work. The latter digital teaching tool is a video-based lecture about coping strategies, problem solving, social support, and time management (Fig. 3).

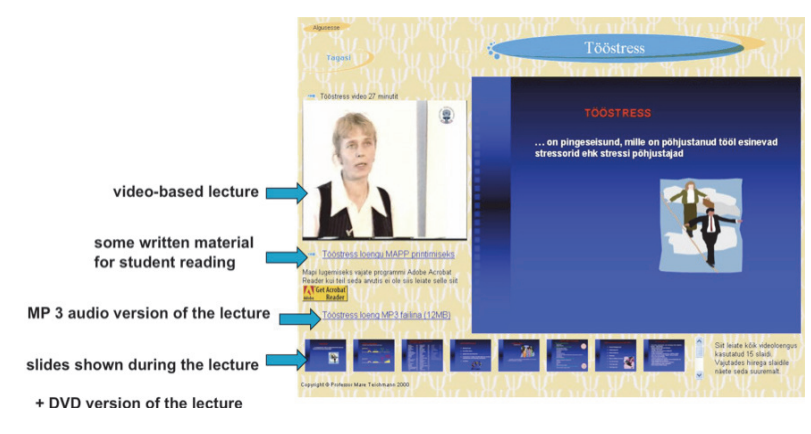

Fig. 3. Digital Teaching Tool "Occupational Stress"

The system was built using PHP implementations for developing and running distributed architecture. We preferred PHP implementations for several reasons. First, they are platform-independent, e.g. it is a model of software that is independent of the specific technological platform used to implement it. Second, an advantage of PHP is that it is possible to get started with little or no cost. Third, video streaming is of little burden to the server. Fourth, it allows necessary flexibility in usage of the digital teaching tools and developing them as means of e-learning. Videos are streamed with PHP Streaming and played with the Flash Video Player by Jeroen Wijering. Both scripts can be downloaded free of charge for noncommercial use. The texts are available in PDF format and users can also download Adobe Acrobat Reader for free.

\section{Sources of Relevant Information}

Sources of information contain some written material for users reading i.e. papers, presentations and articles regarding occupational stress in technical university academics, and coping with stress issues.

\section{E. Video-based Instructions for Technical University Academic Staff}

Instructions were developed on the basis of occupational stress survey results. The evidence based instructions include individual level guidelines for dealing with occupational stressors target more intensive sources of stress at academic work and environment i.e. evaluation of knowledge in society, workload, students and teaching, professional development, university life and relationships, university infrastructure, 
bureaucracy, personal life (work-life balance) and professional identity.

The second part of instructions contains the strategies for coping with stress. Coping generally refers to adaptive or constructive coping strategies, i.e. the strategies that reduce stress level. However, some coping strategies can be considered maladaptive, i.e. increasing the stress level. This happened with academic staff at TUT. One significant difference $(p<0.01)$ between two universities studied in this research was in academic staff members' feelings about their students - in other words, to what extent the students presented a source of stress for the staff members (Students and teaching factor). Students and teaching factor consisted of 20 items, among which 11 items were statistically significantly different between academics at TUT and University of Bordeaux. This suggests that academic staff at TUT use maladaptive unconscious or non-conscious coping strategies (e.g. defense mechanisms) and utilize projection or displacement mechanisms to focus negative feelings of occupational stress upon another individual or group, i.e. upon the students, as scapegoats. The scapegoat theory prejudice springs from frustration among people who are disadvantaged themselves [31]. Scapegoats are typically persons or categories of people with little power, whom others unfairly blame for their own troubles [32, 33, 34, 35, 36]. Blaming students for their different levels of preparation for university studies, for their inadequate study skills, for their low level of preparation, for low study/work motivation, for their absenteeism, for their ineffective time planning and time management, for their unconcern and lack of responsibility, for their low level of discipline or inadequate behavior etc. proposes clearly existence of projective self-defense mechanisms that reduce anxiety but do not solve any problem. Our research results suggest that TUT academics use maladaptive coping style that are emotion-focused and not problem-focused when coping with stress. This empirical evidence clearly shows the importance of taking into account the university-specific sources of pressure for occupational stress intervention.

As occupational stress at modern universities is rather common, we offer a realistic intervention scheme with more effective coping strategies to reduce occupational stress in technical university (Fig. 4).

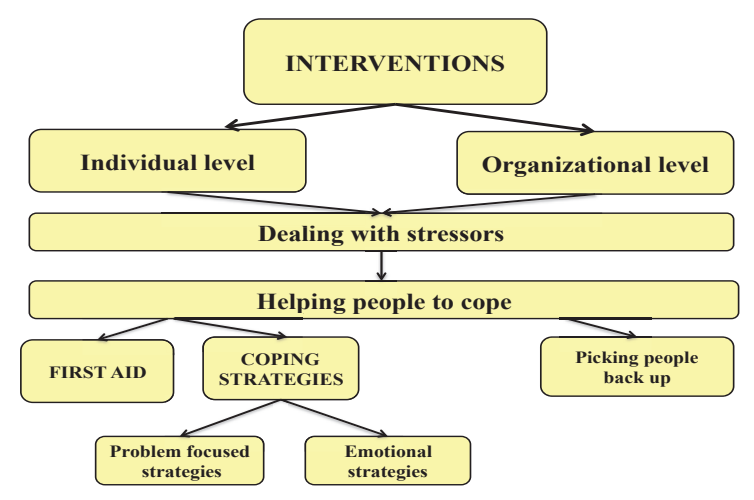

Fig. 4. Occupational Stress Interventions

The data reported here are part from the research project "Occupational stress study and web-based occupational stress prevention system for academic staff of Estonian universities" supported by Primus grant no. 38.2/23 from the European Social Fund
Preventive measures and intervention for occupational stress in technical university academics are addressed on two levels. On individual level it is important to recognize that university teaching is a stressful occupation. The next step is to learn more about occupational stressors in technical university work environment and also to learn dealing with these stressors.

Secondary level occupational stress intervention addresses helping people to cope with stress resulted from using knowledge and skills about coping with stress in general and occupational stress specifically.

\section{CONCLUSIONS}

The starting point for dealing with occupational stress in technical university is recognition of the fact that university teaching, which has traditionally been regarded as a low-stress occupation, is in a modern university an occupation with a high stress risk.

The results of our research suggest that the academics themselves have a lot of opportunities to deal with occupational stressors. In everyday practice it means better workflow planning, personal work-life balance activities, evaluating the necessity of university bureaucracy, enhancing relationships with students, peers and management, and working on constant professional development.

The main purpose of online occupational stress intervention system is to guide technical university academic staff themselves to deal with occupational stress management by using effective coping strategies.

The novelty of the online system is in multiple-choice approach considering of both different university-specific aspects of occupational stress, and primary as well as secondary level stress interventions.

Primary level occupational stress intervention focuses on dealing with stressors by offering psycho-diagnostics: the Academic Occupational Stress Indicator (AcadOSI) and individual feedback for an online user.

Secondary level occupational stress intervention helps people to cope with stress by sharing knowledge, advice and guidance. Attention has been drawn to self-help through information access and also to necessity of having evidencebased guidance to ease coping with stress.

This level in online occupational stress intervention system includes digital teaching tools on "Occupational Stress" and "Coping with Stress", the sources of relevant information, and video-based instructions for coping with more intensive sources of occupational stress.

Although, the online occupational stress intervention system is designed for individual use, it also allows collecting data for occupational stress audit. Occupational stress audit provides directions to organization-based interventions i.e. dealing with occupational stressors at university and helping academics to cope more effectively through various activities which university can undertake to reduce the occupational stress among academic staff. University's role is crucial in the 
tertiary level of occupational stress intervention - taking responsibility for employees who are already suffering from the negative effects of stress. Organization-based interventions include counseling and employee assistance programs for rehabilitation, consulting a stress manager or mental health professional to assist employees to cope with stress [37].

And finally, on societal level, Estonian Labour Inspectorate has contributed to implementation of occupational health and safety legislation, and in cooperation with European Agency for Safety and Health at Work; it provides continuous information about psychological and psychosocial risk factors.

\section{REFERENCES}

[1] European Commission, Directorate_Generale for Employment and Social Affairs, Health and Safety at Work, Guidance on work-related stress. Spice of Life - or Kiss of Death? Luxembourg: Office for Official Publications of the European Communities, 1999.

[2] European Commission, Guidance on work-related stress. Spice of Life or Kiss of Death? Executive Summary, Luxembourg: Office for Official Publications of the European Communities, 2002.

[3] A.H. Winefield, "Stress in university academics," Occupational Stress in the Service Professionals. London: Taylor and Frances, 2003.

[4] C. Biron, J-P. Brun, H. Ivers, "Extent and sources of occupational stress in university staff," Journal of Prevention, Assessment and Rehabilitation, vol. 30, 2008, pp. 511-522

[5] L. Zhang, "Occupational stress and teaching approaches among Chinese academics," Journal of Educational Psychology, 29, 2, 2009, pp. 203219.

[6] G. Kinman, and F. Jones, "Effort-reward imbalance: over-commitment and work-life conflict: testing an expanded model," Journal of Managerial Psychology, vol. 23, 2008, pp. 236-251.

[7] T. Aarrevaara, "Academic freedoma in changing academic world," European Review, vol.18, 2010, pp. 55-69.

[8] U. Teichler, "Diversity of Higher Education in Europe and the Findings of a Comparative Study of the Academic Profession," European Higher Education at the Crossroads, Springer, 2012, pp. 935-959.

[9] N. Gillespie, M. Walsh, A.H. Winefield, J. Dua, C. Stough, "Occupational stress in universities: staff perceptions of the causes, consequences and moderators of stress," Work and Stress, vol. 15, 2001, pp. 53-72.

[10] V. Catano, L. Francis, T. Haines, H. Kirpalani, H. Shannon, B. Stringer, L. Lozanski, "Occupational stress among Canadian university academic staff," Bulletin CAUT. Canadian Association of University Teachers, 2007.

[11] C. Biron, J-P. Brun, H. Ivers, "Extent and sources of occupational stress in university staff," Journal of Prevention, Assessment and Rehabilitation, vol. 30, 2008, pp. 511- 522 .

[12] C. Niven and M.G. Cutler, "The perception of occupational stress and its relation to research and teaching among academic staff," Work and Stress: An International Journal of Work, Health and Organization, vol. 9, 1995, pp. 540-543.

[13] E. Brewer and J. McMahan-Landers, "The relationship between job stress and job satisfaction among industrial and technical teacher educators," Journal of career and Technical Education, vol. 20, 2003.

[14] J. Ramage, "The identification of work place stressors by academic staff at Hutt Valley Polytechnic," Victoria University: Graduate School of Business and Government Management, 2001, Unpublished manuscript.

[15] N. Hardie-Boys, "Workload and stress: a report of ASTE members," Wellington: New Zealand Council for Educational research and Association of Staff in Tertiary Education, 1996.
[16] M. Teichmann and J. Ilvest Jr., "Sourcest of occupational stress in technical university academics," Latest Trends on Engineering Education, WSEAS Press, 2010, pp. 448-453.

[17] M. Teichmann, Ph. Dondon, "Sources of stress in Bordeaux University academics," Recent Researches in Educational Technology, WSEAS Press, 2011, pp. 98-105.

[18] C.L. Cooper, "Coping with stress in organizations: the role of management," Psychosocial Factors at Work and their Relation to Health, World Health Organization, Geneva: 1987.

[19] C.L. Cooper, R.D. Cooper and L.H. Eaker, Living with Stress. UK: Penguin Health, 1988.

[20] C.L. Cooper and P. Dewe, Stress: A Brief History. UK: Blackwell Publishing, 2004.

[21] C.L. Cooper, "Enhancing mental capital and wellbeing at work," Creating Value through Occupational Psychology, The British Psychological Society, Division of Occupational Psychology, 2011, pp. 3-4.

[22] C.S. Carver and J. Connor-Smith, "Personality and coping," Annual Review of Psychology, vol. 61, 2010, pp. 679 - 704.

[23] W. Weiten, M.A. Lloyd, D.S. Dunn, E.Y. Hammer, Psychology Applied to Modern Life: Adjustment in the 21st Century $\left(10^{\text {th }}\right.$ ed.). USA: Wadsworth Cengage Learning, 2012.

[24] L. Brannon and J. Feist, Health Psychology: An Introduction to Behavior and Health $\left(7^{\text {th }}\right.$ ed.). USA: Wadsworth Cengage Learning, 2009.

[25] P.J. Dewe, M.P. O'Drscoll, C.L. Cooper, Coping with Stress. A Review and Critique. UK: Wiley and Sons Ltd., 2010.

[26] M. Teichmann and J. Ilvest, Jr., Engineers' Occupational Stress and Stress Prevention System: E-psychodiagnostics and E-learning, Innovations in E-learning, Instruction Technology, Assessment and Engineering Education, Springer, 2007, pp. 249-255.

[27] M. Teichmann, J. Ilvest, Jr., "Web-based occupational stress prevention system," EAWOP official E-Journal: EAWOP in Practice, vol. 3, 2009, pp. 24-29.

[28] P.E. Spector, "Development of the Work Locus of Control Scale," Journal of Occupational Psychology, vol. 61, 1988, pp. 335-340.

[29] P.E. Spector, C.L. Cooper, J.I. Sanchez, M. O'Driscoll, K. Sparks, P. Bernin, A. Büssing, P. Dewe, P., Hart, L. Lu, K. Miller, L. Renault de Moraes, G.M. Ostrognay, M. Pagon, H. Pitariu, S. Poelmans, P. Radhakrishnan, V. Russinova, V., Salamatov, J. Salgado, S. Shima, O.L. Siu, J.B. Stora, M. Teichmann, T. Theorell, P. Vlerick, M. Westman, M., Widerszal-Bazyl, P. Wong, S.Yu, "Do National Levels of Individualism and Internal Locus of Control Relate To Well-Being: An Ecological Level International Study," Journal of Organizational Behaviour, vol. 22, 2001, pp. 1-18.

[30] P.E. Spector, C.L. Cooper, J.I. Sanchez, M. O’Driscoll, K. Sparks, P. Bernin, A. Büssing, P. Dewe, P., Hart, L. Lu, K. Miller, L. Renault de Moraes, G.M. Ostrognay, M. Pagon, H. Pitariu, S. Poelmans, P. Radhakrishnan, V. Russinova, V., Salamatov, J. Salgado, S. Shima, O.L. Siu, J.B. Stora, M. Teichmann, T. Theorell, P. Vlerick, M. Westman, M., Widerszal-Bazyl, P. Wong, S.Yu, "Locus of Control and Well-Being at Work: How Generalizable Are Western Findings?" Academy of Management Journal, vol. 2, 2002, pp. 443-453.

[31] J. Dollard, L.W. Doob, M.E. Miller, O.H. Mowrer, R.R. Sears, Frustration and aggression. New Haven: Yale University Press, 1939.

[32] J. Davey, Burnout: Stress in the Ministry. New Zealand: Gracewing Fowler Wright Books, 1995.

[33] B.J. Biddle, T.L. Good, I. Goodson, International Handbook of Teachers and Teaching. The Netherlands: Kluwer Academic Publishers, 1997.

[34] C. Maslach, M.P. Leiter, The truth about burnout: how organizations cause personal stress. USA: Wiley, 1997.

[35] C. Maslach, Burnout: The cost of caring. Englewood Clipps, N.J.: Prentice-Hall, 2003.

[36] M. Weimer, M. (2010). Inspired College Teaching: A Career-Long Resource for Professional Growth. USA: Wiley and Sons, 2010.

[37] A.P. Arthur, "Employee Assistance Programmes: The Emperorís New Clothes or Stress Management," Journal of British Guidance and Counselling, vol. 28, 2000, pp. 549-59.

Creative Commons Attribution License 4.0 (Attribution 4.0 International, CC BY 4.0)

This article is published under the terms of the Creative Commons Attribution License 4.0

https://creativecommons.org/licenses/by/4.0/deed.en US 